\title{
A THEORETICAL PREFACE
}

History of art, . . . instructs us that art, every art, constantly strives to break through the fimitations provided by its material, inclining at one time toward this one, at another time toward that one of the other arts.

- Jan Mukarovsky, "The Essence of the Visual

Arts* (1966)
The art of Edward Kienholz has engaged me as both critic and scholar for more than a decade now. It was during the writing of my first essay on his work, in 1978, that I became convinced that Kienholz had created some of the most significant and underrated sculpture of the post-1945 era. And more than a decade later I remain unswayed in my estimation of the importance of the work that he forged on his own until 1972, and thereafter with his wife, Nancy Reddin Kienholz, as an official collaborator.'

Yet in an era that saw the Abstract Expressionist sculpture of David Smith give way to the Minimalist objects of Donald Judd or Tony Smith, Edward Kienholz's large scale narrative tableaux seemed to be something of an anomaly. Barbara Rose articulated the dilemma that his work posed in a 1963 review of his first environmental work, Roxy's (1961): "Kienholz obviously has something to say, but why has he chosen to express himself visually and not verbally?" ("New York Letter," 65).

Both the work created by Kienholz alone and with Reddin Kienholz aspires, in some part, to the condition of literature. Yet in its sheer physicality, its human scale, and its use of detail, the Kienholzes' assemblages and tableaux have an effect quite different from literature. We "read" these works differently than we would a short story, a play, or a novel since we must piece together a tale from the figures and their surrounding environments. Only in the earliest tableaux are there explicitly literary clues, such as the letters in Roxy's and The Birthday (1964), placed in half concealed locales so that the viewer became a voyeur while reading them. We also interpret these tableaux 
differently than we would a narrative painting, for when the tableaux consist of entire rooms we are enveloped by them; they surround us as any room would and so we experience them by piecing together a sequence of visual perceptions and physical sensations rather than viewing them simply as pictorial scenes. Even when a tableau's presentation is predominantly frontal and we view the constructed scene as if the space it occupied were a stage, its physical nature parallels that of the everyday environment. It is not a window on the world but is akin to an altered chunk of the larger environment that once existed-a place that is preserved, entombed, and reconstructed. We are physically inside "the story" or standing in front of it as it were.

Craig Owens, in his essay, "The Allegorical Impulse: Toward a Theory of Postmodernism, " aptly asserts that one of the prominent "strategies" in the visual arts of our moment is "hybridization. "2 The Kienholzes oeuvre firmly demonstrates the validity of this particular strategy. In turn, their art demands that one employ the skills of the literary critic as much as those of the art critic; to be as cognizant of literary history as art history. The insistent confrontation of their art with problematic aspects of the social arena also asks that one view these works as part of a larger tradition of cultural criticism. Ultimately, then, their art insists on an interdisciplinary approach, and I have tried to fulfill that demand in both the overarching framework of my essay and in the individual analyses of selected major works.

This essay-divided into an introduction and four chapters-focuses largely on the work rather than the artists' lives, attempting to illuminate its development: xiii its formal advances, its persistent thematic concern, and its cultural context. Moreover, I have focused on the development of their American work, with much less attention to the art created in Germany. Although there is an overarching unity to their entire output, in both its sensitivity to the cultural resonance of found objects and its formal structure, the work made in and about the United States offers a thoroughgoing critique of life in America which, to my mind, was deserving of a book unto itself. Taken together, the introduction and chapters are an interpretation of this major portion of their oeuvre.

Preceeding each chapter is an interchapter that touches on aspects of both Kienholz's and Reddin Kienholz's lives. This information seemed largely out of place within the sequence of the longer chapters, but valuable nonetheless to highlight events surrounding the public dissemination and reception of their art. The chronology of a given interchapter loosely corresponds to that of the chapter that follows it. (Moreover, I have provided a standard chronology at the close of $m y$ essay.) Ultimately, however, this study is a biography of their American work. I have aspired to trace the development of this oeuvre as it has taken place over the last three decades and more so we can better understand its marked contribution to both American art and art in general. 


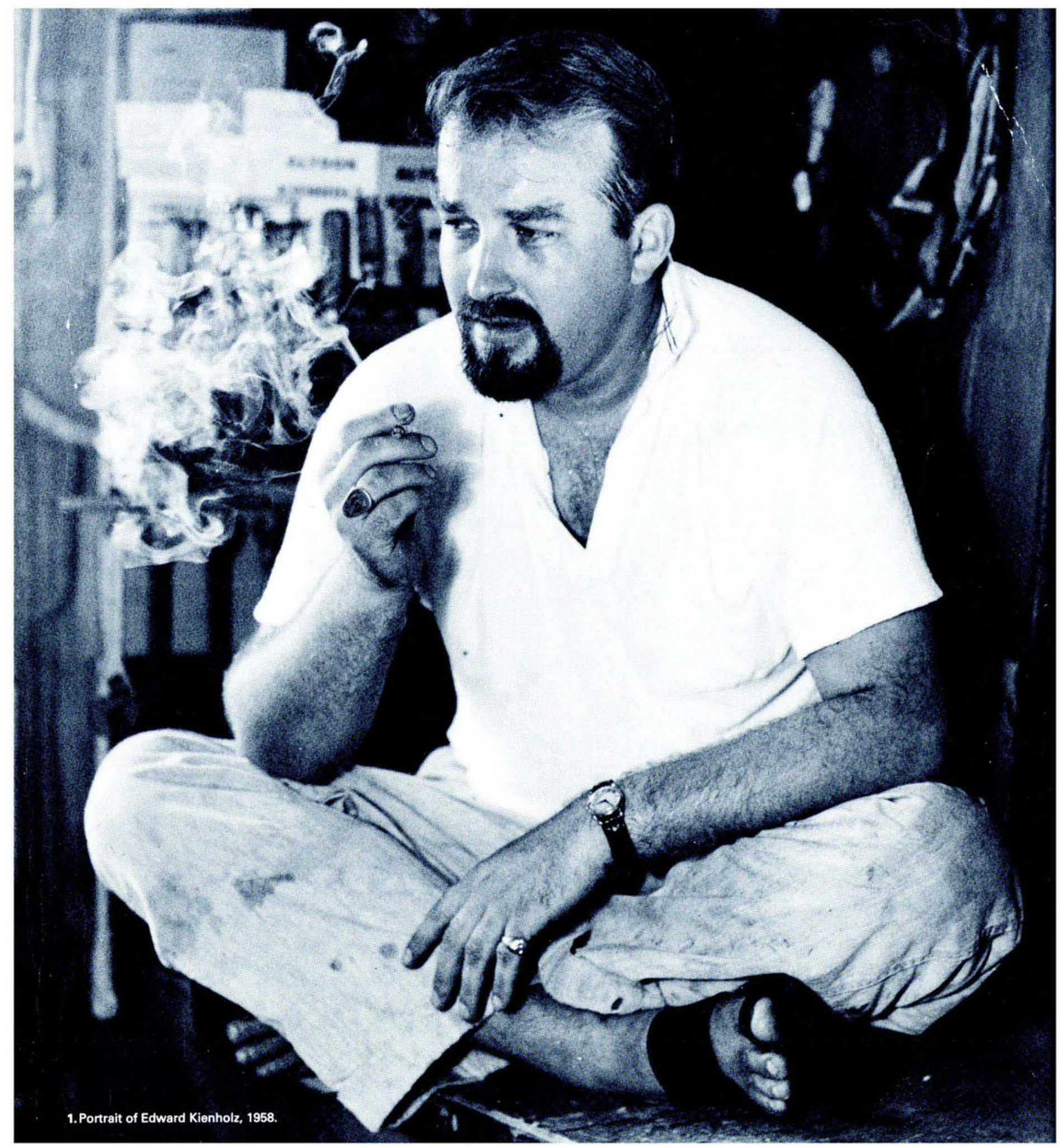

